\title{
An Empirical Study of the Chinese Marriage Market: "Leftover" or Not?
}

\author{
Qingqing Peng1 ${ }^{*}$, Lei Li ${ }^{2}$ \\ ${ }^{1}$ School of Economics and Management, Tsinghua University, Beijing, China \\ ${ }^{2}$ Department of Economics, University of Zurich, Zürich, Switzerland \\ Email: *pengqq.07@sem.tsinghua.edu.cn, lei.li@econ.uzh.ch
}

How to cite this paper: Peng, Q.Q. and Li, L. (2017) An Empirical Study of the Chinese Marriage Market: "Leftover" or Not? Open Journal of Social Sciences, 5, 229-247. https://doi.org/10.4236/jss.2017.58019

Received: July 7, 2017

Accepted: August 22, 2017

Published: August 25, 2017

Copyright $\odot 2017$ by authors and Scientific Research Publishing Inc. This work is licensed under the Creative Commons Attribution International License (CC BY 4.0).

http://creativecommons.org/licenses/by/4.0/

\begin{abstract}
Using census data from 1990 to 2010, this paper describes the trend of the Chinese marriage market focusing on "leftover men" and "leftover women". In general, it was identified that there was an increasing share of being single for young and more educated population. The share of single population for less educated men after age 35 was higher than other age groups across the years, providing consistent evidence for leftover men. Meanwhile, more educated women showed no clear difference in marriage rate than others in their late 30s. This study further found that increasing comparative supply of men and more educated women due to demographic change and education reform explains the phenomena observed. In addition, women who get married later were found to have husbands showing disadvantages in age and education level, while men displayed no similar pattern, suggesting that Chinese women might lower their selecting standard as their age increases.
\end{abstract}

\section{Keywords}

Single Rate, Gender Difference, "Leftover Men”, "Leftover Women”, Marriage Choice

\section{Introduction}

Recently, researchers, policy makers and social media in China have discussed widely about the "leftover women" and "leftover men" phenomena. The discussion on leftover men is mainly based on the skewed sex ratio in China. The one-child policy provoked the traditional son preference, leading to soaring sex ratio at birth since 1970s (Li, 2007, [1]; Loh et al., 2015, [2]), Tuljapurkar, et al. (1995) [3] forecasted that China would have one million excess men in the mar- 
riage market by 2010 . This number is predicted to be 30 million in $2030^{1}$. Massive population of single men could not only cause distortion in the marriage market, but also threaten social stability and economic development (Wei et al., 2011, [4]; Edlund et al., 2013, [5]).

Under this circumstance, the leftover women phenomenon seems to be puzzling. A government report in 2007 aiming at "upgrading quality of new-births" firstly introduced the terminology of "leftover women", referring to those highly educated but unmarried women ${ }^{2}$. It has been identified that more years in education naturally postpone the time for entering the marriage market, as studies using US data show that women with college education put off marriage compared to lower educated groups. However, they show higher final marriage rates between age 30 to 50 (Goldstein et al., 2001, [6]; Lundberg, 2007, [7]). One of the earliest studies using China's data shows a different trend than the results from the US. Specifically, Qian et al. (2014) [8] found that the marriage possibility decreases as the education of women increases after age 30 while the opposite was true for men. The situation might be worsened along the education reform started from 1980s, which admitted comparatively more female than male students in higher education (Bauer et al. 1992, [9]). Wu et al. (2014) [10] estimated the effect of college expansion on marriage market and reported that college graduates' marriage rate dropped after the expansion, while the decline was greater for women. Existing literature has discussed Chinese marriage market from different angles concentrated on the gender difference in the changes $(\mathrm{Wu}$ et al., 2014, [10]; Zhang et al., 2015, [11]); however, the trend of the market and the existence of leftover women remain in question.

Experiencing continuous drop in the fertility rate and aging society, the discussion on leftover women and leftover men has become heated but there still lacks critical evidence to support this assertion. Whether to get married or not? When to get married? Who to marry with? The answers to these questions are still in vague. Using National Bureau of Statistics (NBS) Population Census datasets from 1990 to 2010, we display the trend of Chinese marriage market and empirically test the existence and mechanism of leftover men and leftover women. This paper found that the share of being single for low educated men was higher than counterparts because of excess supply in the market, or to say low educated men are leftover after age 35 . Meanwhile, highly educated women postpone their marriage choice for increasing competence, but show no significant difference after age 35, providing no evidence as leftover women. However, women who get married late in life might suffer from decline in quality of marriage considering husband's age and education.

The remainder of the paper proceeds as follows. Section 2 describes the datasets we employed and the summary statistics showing the trend of Chinese mar-

${ }^{1}$ Source: National population development plan (2016-2030).

${ }^{2}$ Source: Decision of the central committee of the communist party of China on strengthen population, birth controlling and solving population problem. 
riage market. Section 3 provides the empirical results discussing the existence and mechanism of leftover women and leftover men. Section 4 deals with the conclusion.

\section{Data and Summary Statistics}

To analyze the trend of Chinese marriage market, we adapted 4 datasets: $1 \%$ sample of 1990 and 2000 NBS National Population Census, 0.2\% sample of 2005 NBS Population Survey and national aggregate statistics of 2010 NBS National Population Census, which are the most representative data with sufficient size to capture the feature of the changes in the Chinese marriage market. Each dataset includes various information on individual characteristics, supporting our study considering how the trend might differ across gender, hukou, education and age.

This paper further restricted the sample to the population aged 15 and above according to NBS rules in collecting marriage information. Using the marital status reported in the datasets, we categorized the population by whether the individual has or has not marriage experience, implying that we are mainly considering the trend of first marriage market ${ }^{3}$. To measure the trend, we calculated the share of being single using the following:

$$
\begin{aligned}
\text { single rate }_{\mathrm{i}, \mathrm{e}, \mathrm{a}, \mathrm{s}} & =\frac{\text { single }_{\mathrm{i}, \mathrm{e}, \mathrm{a}, \mathrm{s}}}{\text { total populaton }_{\mathrm{i}, \mathrm{e}, \mathrm{a}, \mathrm{s}}} \\
& =\frac{\text { single }_{\mathrm{i}, \mathrm{e}, \mathrm{a}, \mathrm{s}}}{\text { single }_{\mathrm{i}, \mathrm{e}, \mathrm{a}, \mathrm{s}}+\text { married }_{\mathrm{i}, \mathrm{e}, \mathrm{a}, \mathrm{s}}+\operatorname{divorced}_{\mathrm{i}, \mathrm{e}, \mathrm{a}, \mathrm{s}}+\operatorname{widowed~}_{\mathrm{i}, \mathrm{e}, \mathrm{a}, \mathrm{s}}}
\end{aligned}
$$

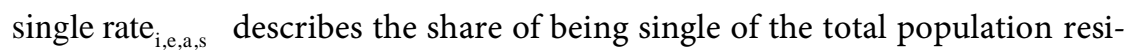
dency at district i with education e, age a and sex s ( total populaton $\mathrm{i}_{\mathrm{i}, \mathrm{e}, \mathrm{a}, \mathrm{s}}$ ), referred to as single rate in following sections. Similarly, $\operatorname{married}_{\mathrm{i}, \mathrm{e}, \mathrm{a}, \mathrm{s}}$, $\operatorname{divorced}_{\mathrm{i}, \mathrm{e}, \mathrm{a}, \mathrm{s}}$, widowed $_{\mathrm{i}, \mathrm{e}, \mathrm{a}, \mathrm{s}}$ describes the share of being married, being divorced and being widowed of the total population respectively.

Another result variable we explored was the age at first marriage, which is available in 2000 and 2005 census. Individuals reporting first marriage age younger than 15 were excluded from the sample according to NBS rules.

To explore the matching pattern in Chinese marriage market, this paper further constructed a matched couple data using 1990, 2000 and 2005 censuses. The methodology employed is as follows. Using the "relationship with household head" variable in the data, we matched married individuals with the opposite gendered one reporting as married and the corresponding category in the relationship variable, specifically matching "household head" with "spouse of household head", "son/daughter" with "son/daughter in law". For 1990 census, the survey did not differentiate "son/daughter" from "son/daughter in law", so the sample was further restricted requiring that the age gap between the couple should be less than 10 years in order to exclude possible mismatch between

${ }^{3}$ The incentive and mechanism of re-marriage market might be entirely different from first marriage decisions, which we would like to explore in further studies if possible. 
brothers and sisters ${ }^{4}$. For the 2000 and 2005 census, we matched couple reporting the same first marriage year which could further exclude re-married couples.

We showed the trend of single rates in Chinese marriage market by hukou, gender, age and education level as presented in Table 1 and Table 2, and also we categorized the full sample to three education levels: middle school and below, high school, college and above so as to discuss the difference across groups. The

Table 1. Single rates by gender, age group, education level and census year (urban).

\begin{tabular}{|c|c|c|c|c|c|c|c|c|}
\hline \multirow[b]{2}{*}{ Age group } & \multicolumn{4}{|c|}{ Women } & \multicolumn{4}{|c|}{ Men } \\
\hline & 1990 & 2000 & 2005 & 2010 & 1990 & 2000 & 2005 & 2010 \\
\hline \multicolumn{9}{|c|}{ Middle school and below } \\
\hline $15-22$ & $88.9 \%$ & $89.6 \%$ & $90.3 \%$ & $84.5 \%$ & $96.3 \%$ & $97.6 \%$ & $98.0 \%$ & $94.4 \%$ \\
\hline $23-29$ & $15.1 \%$ & $16.6 \%$ & $19.5 \%$ & $24.1 \%$ & $37.9 \%$ & $37.2 \%$ & $42.9 \%$ & $43.7 \%$ \\
\hline $30-34$ & $1.2 \%$ & $2.4 \%$ & $3.4 \%$ & $4.7 \%$ & $6.1 \%$ & $8.5 \%$ & $12.2 \%$ & $11.6 \%$ \\
\hline $35-39$ & $0.8 \%$ & $0.9 \%$ & $1.5 \%$ & $1.9 \%$ & $2.4 \%$ & $3.6 \%$ & $4.8 \%$ & $5.4 \%$ \\
\hline $40-44$ & $0.5 \%$ & $0.5 \%$ & $0.8 \%$ & $1.0 \%$ & $1.3 \%$ & $2.2 \%$ & $3.3 \%$ & $3.2 \%$ \\
\hline $45-49$ & $0.2 \%$ & $0.4 \%$ & $0.5 \%$ & $0.7 \%$ & $1.0 \%$ & $1.4 \%$ & $2.2 \%$ & $2.4 \%$ \\
\hline $50-54$ & $0.2 \%$ & $0.3 \%$ & $0.5 \%$ & $0.4 \%$ & $0.9 \%$ & $1.1 \%$ & $1.5 \%$ & $2.0 \%$ \\
\hline $55-59$ & $0.2 \%$ & $0.2 \%$ & $0.4 \%$ & $0.4 \%$ & $0.8 \%$ & $0.9 \%$ & $1.1 \%$ & $1.6 \%$ \\
\hline \multicolumn{9}{|c|}{ High school } \\
\hline $15-22$ & $94.8 \%$ & $97.0 \%$ & $97.4 \%$ & $96.2 \%$ & $98.4 \%$ & $99.2 \%$ & $99.5 \%$ & $98.6 \%$ \\
\hline $23-29$ & $18.1 \%$ & $26.3 \%$ & $32.5 \%$ & $37.5 \%$ & $37.4 \%$ & $46.4 \%$ & $51.7 \%$ & $54.5 \%$ \\
\hline $30-34$ & $1.9 \%$ & $3.1 \%$ & $5.1 \%$ & $7.8 \%$ & $4.9 \%$ & $7.6 \%$ & $11.9 \%$ & $13.9 \%$ \\
\hline $35-39$ & $1.1 \%$ & $1.0 \%$ & $1.9 \%$ & $3.2 \%$ & $1.1 \%$ & $2.4 \%$ & $4.2 \%$ & $5.7 \%$ \\
\hline $40-44$ & $0.8 \%$ & $0.6 \%$ & $0.9 \%$ & $1.6 \%$ & $0.8 \%$ & $1.2 \%$ & $2.0 \%$ & $2.9 \%$ \\
\hline $45-49$ & $0.4 \%$ & $0.5 \%$ & $0.8 \%$ & $0.9 \%$ & $0.6 \%$ & $0.5 \%$ & $1.3 \%$ & $1.8 \%$ \\
\hline $50-54$ & $0.4 \%$ & $0.6 \%$ & $0.5 \%$ & $0.6 \%$ & $0.6 \%$ & $0.5 \%$ & $0.6 \%$ & $1.2 \%$ \\
\hline $55-59$ & $0.4 \%$ & $0.3 \%$ & $0.4 \%$ & $0.6 \%$ & $0.6 \%$ & $0.4 \%$ & $0.5 \%$ & $0.7 \%$ \\
\hline \multicolumn{9}{|c|}{ College and above } \\
\hline $15-22$ & $98.7 \%$ & $98.6 \%$ & $98.2 \%$ & $98.7 \%$ & $99.6 \%$ & $99.7 \%$ & $99.6 \%$ & $99.5 \%$ \\
\hline $23-29$ & $36.7 \%$ & $37.0 \%$ & $49.8 \%$ & $55.3 \%$ & $51.0 \%$ & $53.6 \%$ & $64.4 \%$ & $67.2 \%$ \\
\hline $30-34$ & $6.4 \%$ & $4.2 \%$ & $6.5 \%$ & $10.7 \%$ & $4.5 \%$ & $7.2 \%$ & $11.9 \%$ & $15.1 \%$ \\
\hline $35-39$ & $2.9 \%$ & $1.6 \%$ & $2.7 \%$ & $4.2 \%$ & $1.0 \%$ & $1.6 \%$ & $3.0 \%$ & $4.9 \%$ \\
\hline $40-44$ & $1.9 \%$ & $1.6 \%$ & $1.0 \%$ & $2.1 \%$ & $0.5 \%$ & $0.6 \%$ & $0.9 \%$ & $2.2 \%$ \\
\hline $45-49$ & $0.7 \%$ & $1.5 \%$ & $1.2 \%$ & $1.3 \%$ & $0.4 \%$ & $0.3 \%$ & $0.6 \%$ & $1.1 \%$ \\
\hline $50-54$ & $0.4 \%$ & $1.0 \%$ & $1.1 \%$ & $1.2 \%$ & $0.6 \%$ & $0.4 \%$ & $0.3 \%$ & $0.7 \%$ \\
\hline $55-59$ & $0.7 \%$ & $0.7 \%$ & $1.0 \%$ & $1.1 \%$ & $0.8 \%$ & $0.3 \%$ & $0.2 \%$ & $0.5 \%$ \\
\hline
\end{tabular}

Data source: Census 1990-2010.

${ }^{4}$ The Chinese Census is practiced as household level under hukou system. For Chinese family with multiple children, it is most likely for the children to move out the household (get a new hukou) at the time of marriage and have one child (with his/her spouse) stay and take the responsibility of taking care of aging parents, so it is unlikely to have two or more close-aged grown-up married siblings in the same household. 
Table 2. Single rates by gender, age group, education level and census year (rural).

\begin{tabular}{|c|c|c|c|c|c|c|c|c|}
\hline \multirow[b]{2}{*}{ Age group } & \multicolumn{4}{|c|}{ Women } & \multicolumn{4}{|c|}{ Men } \\
\hline & 1990 & 2000 & 2005 & 2010 & 1990 & 2000 & 2005 & 2010 \\
\hline \multicolumn{9}{|c|}{ Middle school and below } \\
\hline $15-22$ & $79.7 \%$ & $87.4 \%$ & $86.2 \%$ & $79.9 \%$ & $89.9 \%$ & $96.3 \%$ & $95.9 \%$ & $92.3 \%$ \\
\hline $23-29$ & $8.6 \%$ & $11.7 \%$ & $15.4 \%$ & $19.9 \%$ & $24.5 \%$ & $30.0 \%$ & $36.2 \%$ & $36.3 \%$ \\
\hline $30-34$ & $0.3 \%$ & $0.9 \%$ & $1.7 \%$ & $3.9 \%$ & $9.5 \%$ & $7.9 \%$ & $10.8 \%$ & $12.8 \%$ \\
\hline $35-39$ & $0.1 \%$ & $0.3 \%$ & $0.5 \%$ & $1.2 \%$ & $7.6 \%$ & $5.3 \%$ & $5.8 \%$ & $7.7 \%$ \\
\hline $40-44$ & $0.2 \%$ & $0.1 \%$ & $0.3 \%$ & $0.5 \%$ & $6.8 \%$ & $5.6 \%$ & $4.4 \%$ & $5.2 \%$ \\
\hline $45-49$ & $0.2 \%$ & $0.1 \%$ & $0.2 \%$ & $0.3 \%$ & $6.9 \%$ & $5.4 \%$ & $4.7 \%$ & $4.2 \%$ \\
\hline $50-54$ & $0.2 \%$ & $0.1 \%$ & $0.2 \%$ & $0.2 \%$ & $6.2 \%$ & $5.5 \%$ & $4.7 \%$ & $4.6 \%$ \\
\hline $55-59$ & $0.2 \%$ & $0.1 \%$ & $0.2 \%$ & $0.2 \%$ & $4.9 \%$ & $5.8 \%$ & $4.7 \%$ & $4.6 \%$ \\
\hline \multicolumn{9}{|c|}{ High school } \\
\hline $15-22$ & $93.0 \%$ & $96.6 \%$ & $97.4 \%$ & $96.4 \%$ & $95.2 \%$ & $99.0 \%$ & $99.3 \%$ & $98.4 \%$ \\
\hline $23-29$ & $13.5 \%$ & $29.8 \%$ & $34.8 \%$ & $37.0 \%$ & $16.2 \%$ & $39.9 \%$ & $47.2 \%$ & $48.2 \%$ \\
\hline $30-34$ & $0.6 \%$ & $2.3 \%$ & $4.0 \%$ & $6.0 \%$ & $2.6 \%$ & $4.9 \%$ & $8.4 \%$ & $10.0 \%$ \\
\hline $35-39$ & $0.3 \%$ & $0.4 \%$ & $1.2 \%$ & $1.9 \%$ & $2.1 \%$ & $1.4 \%$ & $2.6 \%$ & $4.0 \%$ \\
\hline $40-44$ & $0.4 \%$ & $0.1 \%$ & $0.2 \%$ & $0.7 \%$ & $1.8 \%$ & $1.1 \%$ & $1.2 \%$ & $1.9 \%$ \\
\hline $45-49$ & $0.1 \%$ & $0.1 \%$ & $0.3 \%$ & $0.3 \%$ & $2.1 \%$ & $1.2 \%$ & $0.8 \%$ & $1.0 \%$ \\
\hline $50-54$ & $0.0 \%$ & $0.1 \%$ & $0.1 \%$ & $0.2 \%$ & $2.8 \%$ & $1.3 \%$ & $1.1 \%$ & $0.8 \%$ \\
\hline $55-59$ & $0.0 \%$ & $0.2 \%$ & $0.0 \%$ & $0.3 \%$ & $3.6 \%$ & $1.4 \%$ & $1.0 \%$ & $0.8 \%$ \\
\hline \multicolumn{9}{|c|}{ College and above } \\
\hline $15-22$ & $97.6 \%$ & $97.4 \%$ & $97.5 \%$ & $97.9 \%$ & $97.1 \%$ & $99.3 \%$ & $99.0 \%$ & $99.1 \%$ \\
\hline $23-29$ & $50.9 \%$ & $52.5 \%$ & $57.0 \%$ & $53.7 \%$ & $41.4 \%$ & $60.1 \%$ & $66.8 \%$ & $64.3 \%$ \\
\hline $30-34$ & $1.7 \%$ & $5.6 \%$ & $11.2 \%$ & $5.9 \%$ & $1.6 \%$ & $8.4 \%$ & $13.4 \%$ & $9.5 \%$ \\
\hline $35-39$ & $2.7 \%$ & $2.2 \%$ & $1.8 \%$ & $1.7 \%$ & $2.7 \%$ & $3.2 \%$ & $1.8 \%$ & $2.5 \%$ \\
\hline $40-44$ & $0.0 \%$ & $1.0 \%$ & $1.0 \%$ & $0.9 \%$ & $2.0 \%$ & $1.5 \%$ & $2.2 \%$ & $1.0 \%$ \\
\hline $45-49$ & $0.0 \%$ & $1.2 \%$ & $0.0 \%$ & $0.5 \%$ & $1.4 \%$ & $0.5 \%$ & $1.3 \%$ & $0.5 \%$ \\
\hline $50-54$ & $0.0 \%$ & $0.0 \%$ & $0.0 \%$ & $0.5 \%$ & $4.8 \%$ & $1.8 \%$ & $0.0 \%$ & $0.3 \%$ \\
\hline $55-59$ & $0.0 \%$ & $0.0 \%$ & $0.0 \%$ & $0.5 \%$ & $4.6 \%$ & $3.0 \%$ & $4.0 \%$ & $0.3 \%$ \\
\hline
\end{tabular}

Data source: Census 1990-2010.

first age group boundary was set at 22, the age expected for would be couples to have finished college/university, while further age grouping was designed to cut at every 5 years to investigate how marriage decision shifts through age (Wu et al., 2014, [10]). The upper age boundary for Table 1 and Table 2 was set at 60, the common limit for the labour age in China.

From Table 1 and Table 2, we observed that single rates of all population groups dropped significantly after age 40 to a level which is not of primary interest (all less than 5\% excepted for men with middle school or below education). Hence, we concentrated mainly on the population younger than 40 and might try to explore the full picture in further studies. Generally, urban residents 
have higher single rates than rural dwellers; men have higher single rates than women of the same age group.

For the youngest subjects in the sample aged 15 to 22 , single rates were high, around $90 \%$ for all categories except the rural women with middle school education or below. It is clear that if males or females spend more years in education, naturally they postpone their entering into the marriage market. Better developed parts of China have lower percentage of early marriage. As we are primarily discussing the difference of marriage choice across gender and education levels, we further restricted the sample to age 23 and above, which allows the population to have the chance to finish higher education.

For urban residents of all education levels aged 23 to 29, the single rates increase throughout the years. In urban population also, the gap between college group and above and high school group increased from 10.7\% in 2000 to $17.9 \%$ in 2010 for women and from $7.2 \%$ to $12.8 \%$ for men. Meanwhile, the gap for rural population slightly decreased. One possible reason is that college and university education is one of the few channels to change hukou in China, so people with college education might just enter the urban marriage market instead. We show the education composition of the sample by year and hukou in Figure 1 and it can be seen that the education distribution is significantly different across hukou types. For clearer comparison, we further grouped the individuals by assigning urban individuals with college education and above and rural individuals with high school education and above as high education group, the rest as low education group 5 .

Gender difference in single rate of individuals with same education is important when discussing leftover women or leftover men in the marriage market. For urban population aged 23 to 29 , we observed that the gender gap in college education and above group decreased from 16.6\% in 2000 to $11.9 \%$ in 2010. This means that there are comparatively more single young women than men

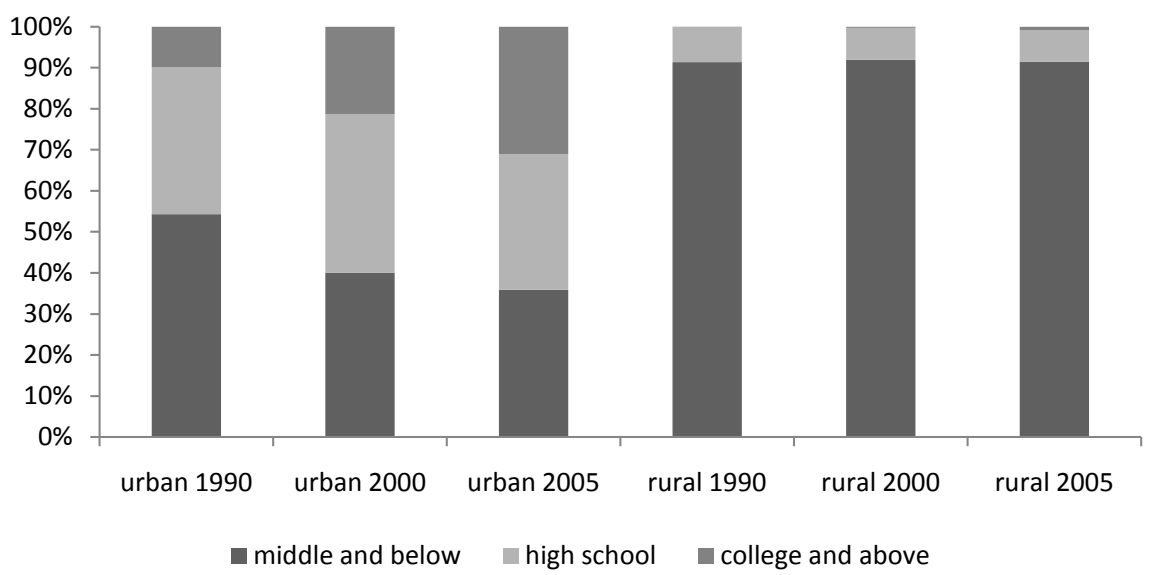

Figure 1. Education level of population by Hukou and census year. Data source: Census 1990-2005.

${ }^{5}$ The criteria allow at least $10 \%$ of the population in high education group while the rest as low education group for each year and hukou type. 
throughout the years. However, men in general still had higher single rate than women for all education groups in each census year. For high education group aged 35 and above, the single rate of men increased slightly compared to women, not supporting leftover women. Meanwhile, the gender gap for low education group was increasing through census years. Especially for rural population, it increased from $7 \%$ in 2000 to $8.9 \%$ in 2010 for age 30 to 34 , and from $4.8 \%$ to $6.5 \%$ for age 35 to 39 , supporting the view of having leftover men.

Table 1 and Table 2 show the trend of single rates through census year. Using the data across two decades (1990 to 2010), we were able to describe the marriage choice of the 1960-1970 cohort from age 20 to 45 . Figure 2 shows the trend of single rates of the cohort by gender, education and hukou. From the graph we observed that people in the high education group had higher single rate during their 20 s in general. The age for $50 \%$ of the population to get married for urban high educated women was approximately two years later than low educated ones, while the difference was about one year for men. However, the gap between the groups shrink significantly as age increases; for urban population at age 35 , the single rate was $1.4 \%$ for low educated women, $4.2 \%$ for low educated men, $2.3 \%$ for high educated women and $2.9 \%$ for high educated men. Meanwhile for rural population, the low educated men group showed higher single rate than other sub-groups after age 25 . At age 40 , the single rate was $0.7 \%$ for low educated women, $1.1 \%$ for high educated women, $2.1 \%$ for high educated men, but $5.9 \%$ for low educated men. The similar trend was observed for the cohort born in 1971 to 1975 from age 25 to 40. From Figure 2, we see that high education postponed individuals' marriage choice, but there was no clear difference in single rate between high educated women and other sub-groups after age 35. This finding does not support leftover women; for low educated men, especially with rural hukou, they did have consistently higher single rate than other groups, showing evidence for leftover men.
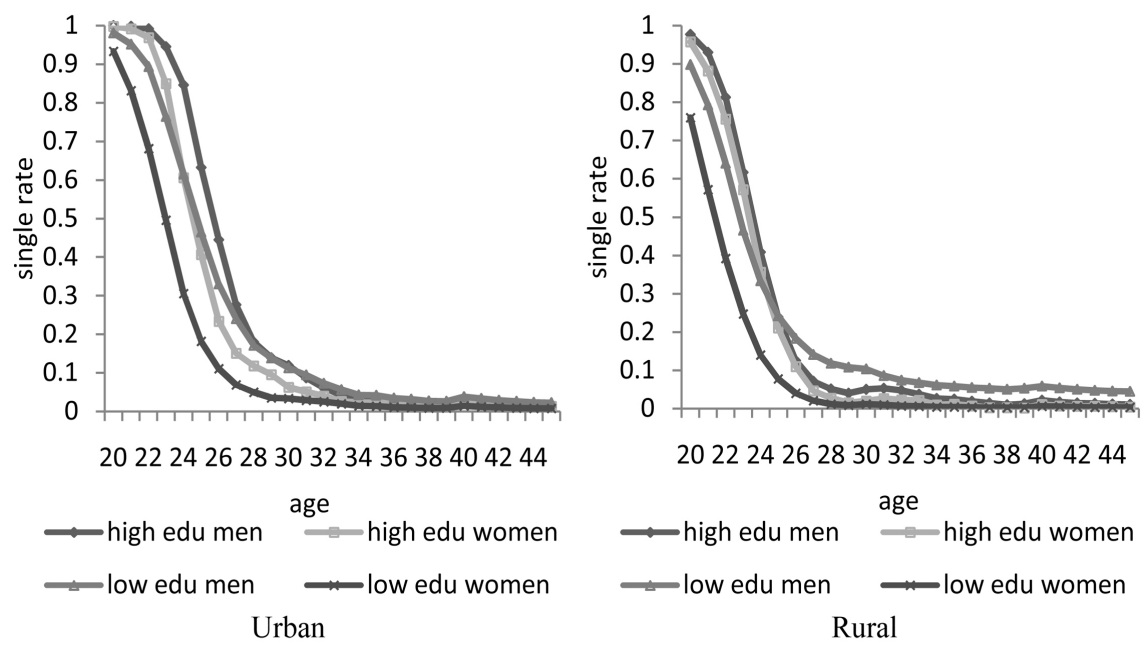

Figure 2. Trend of single rates of cohort born from 1960 to 1970 by gender and education. Data source: Census 1990-2010. 
We further explored the first marriage age of Chinese population by gender, education and hukou in Figure 3. It is clear that the average first marriage age increased along the year, which is parallel with increasing openness of the society and population mobility. For urban residents, high educated men who got married in 1990 had an average age of 25.5, while it was 23.9 for high educated women, 25 for low educated men, and 23.2 for low educated women. The numbers increased to 28, 25.9, 27.2 and 24.9 in 2005. Although the high educated women postponed their marriage compared to low educated women, the gender gap in high education group is comparatively consistent. For rural population, it is clear that the difference in average first marriage age between low educated men and women was expanding through the years, from 1.7 in 1990 to 2.55 in 2005 , showing growing difficulty for rural low educated men to realize marriage match.

\section{Empirical Analysis}

In this section we empirically examined the trend of Chinese marriage market using the census data of 1990, 2000, and 2005. We employed the Linear Possibility Model (LPM) to determine marriage trend as follow:

$$
\operatorname{Pr}\left(\text { single }=1 \mid X_{i}\right)_{p}=\beta_{0}+\beta_{1} \text { type }_{i}+\beta_{2} \operatorname{group}_{i} * T_{i}+\gamma_{1} Y_{i}+\gamma_{2} Z_{p}+\varepsilon_{i, p}
$$

The dependent variable is the marriage status of individual $i$, assigned as 1 for

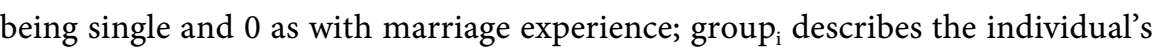
type categorized by gender and education, including dummy variables for low educated women, low educated men, high educated women and high educated men $^{6}$; as we were mainly discussing the trend in marriage market, $T_{i}$ implies
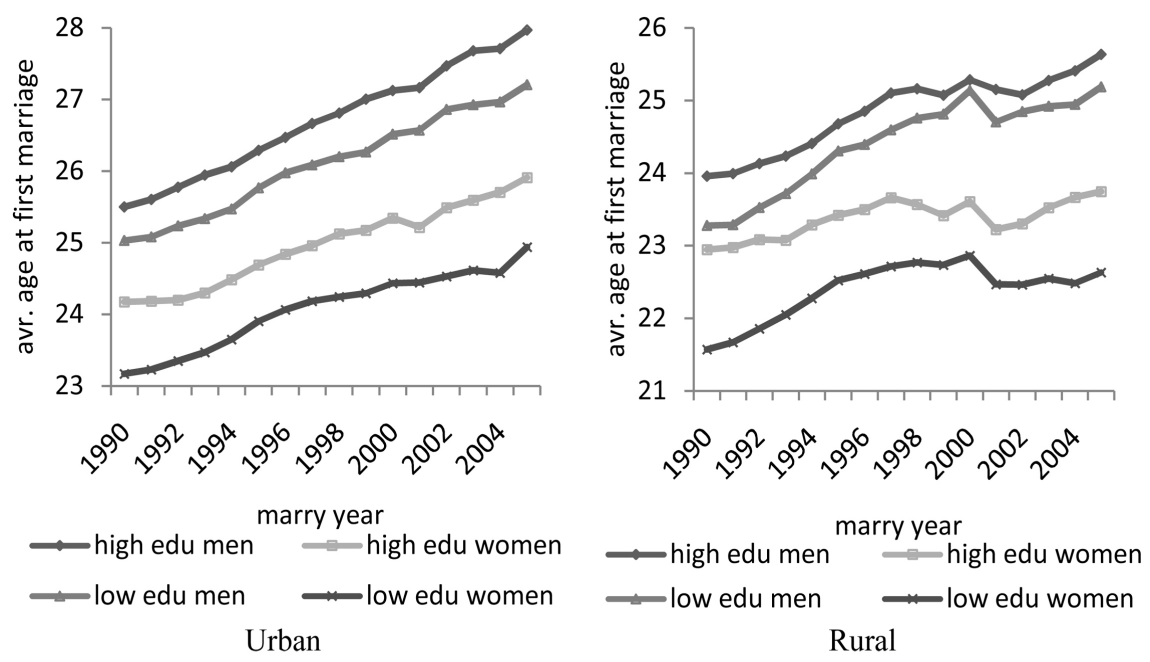

Figure 3. Trend of average first marriage age by gender and education. Data source: Census 2000-2005.

${ }^{6}$ Similar to Section 2, the criteria categorizing education group is different across hukou type. Rural: high education group $=$ high school and above, low education group = middle school and below; Urban: high education group $=$ college and above, low education group $=$ high school and below. 
the census year the individual $i$ is surveyed, meaning dummy variables for 1990, 2000, 2005; $Y_{i}$ describes individual i's personal characteristics, including age; $Z_{p}$ is the province fixed effect and $\varepsilon_{i, p}$ is the random component. As we were mainly interested in the phenomena of leftover women and leftover men, we chose the low educated women as the control group for a clearer comparison. From Table 1 and Table 2 we observed that population's single rate dropped to very low level after age 40 , we chose the sample age 23 to 39 as the group for empirical study and age 40 to 44 for additional information. Regression results by hukou and age group are shown in Table 3 and Table 4.

Column 1 in Table 3 shows the regression result of urban population aged 23 to 29. It is clear that the high educated group had higher single rate than low

Table 3. OLS: Trend of marriage market (urban).

\begin{tabular}{|c|c|c|c|c|}
\hline Dependent variable: Being single $=1$ & (1) & (2) & (3) & $(4)$ \\
\hline Age group & $23-29$ & $30-34$ & $35-39$ & $40-44$ \\
\hline \multirow{2}{*}{ Low edu. women ${ }^{\star} 2000$} & $0.066^{* * *}$ & $0.012^{* * *}$ & $0.002^{* * *}$ & 0.000 \\
\hline & $(0.001)$ & $(0.001)$ & $(0.000)$ & $(0.000)$ \\
\hline \multirow{2}{*}{ Low edu. women ${ }^{\star} 2005$} & $0.081^{\star * \star}$ & $0.021^{* * *}$ & $0.007^{\star * *}$ & $0.002^{* * *}$ \\
\hline & $(0.003)$ & $(0.001)$ & $(0.001)$ & $(0.001)$ \\
\hline \multirow{2}{*}{ Low edu. men } & $0.203^{* * *}$ & $0.039^{* * *}$ & $0.011^{* * *}$ & $0.007^{\star * \star}$ \\
\hline & $(0.001)$ & $(0.001)$ & $(0.001)$ & $(0.000)$ \\
\hline \multirow{2}{*}{ Low edu. men ${ }^{\star} 2000$} & $0.068^{\star * *}$ & $0.028^{* * *}$ & $0.011^{\star * *}$ & $0.005^{\star * *}$ \\
\hline & $(0.002)$ & $(0.001)$ & $(0.001)$ & $(0.001)$ \\
\hline \multirow{2}{*}{ Low edu. men ${ }^{\star} 2005$} & $0.087^{* * *}$ & $0.061^{* * *}$ & $0.024^{* * *}$ & $0.013^{* * *}$ \\
\hline & $(0.003)$ & $(0.002)$ & $(0.001)$ & $(0.001)$ \\
\hline \multirow{2}{*}{ High edu. women } & $0.162^{* * *}$ & $0.047^{* * *}$ & $0.019^{* * *}$ & $0.012^{* * *}$ \\
\hline & $(0.003)$ & $(0.004)$ & $(0.002)$ & $(0.002)$ \\
\hline \multirow{2}{*}{ High edu. women ${ }^{\star} 2000$} & $0.032^{* * *}$ & $-0.024^{* * *}$ & $-0.011^{* * *}$ & -0.001 \\
\hline & $(0.004)$ & $(0.004)$ & $(0.002)$ & $(0.003)$ \\
\hline \multirow{2}{*}{ High edu. women ${ }^{\star} 2005$} & $0.097^{\star \star *}$ & $-0.009^{\star *}$ & -0.004 & $-0.008^{\star * *}$ \\
\hline & $(0.005)$ & $(0.004)$ & $(0.003)$ & $(0.003)$ \\
\hline \multirow{2}{*}{ High edu. men } & $0.300^{* * *}$ & $0.029^{* * *}$ & 0.001 & -0.001 \\
\hline & $(0.002)$ & $(0.002)$ & $(0.001)$ & $(0.001)$ \\
\hline \multirow{2}{*}{ High edu. men ${ }^{\star} 2000$} & $0.066^{* * *}$ & $0.025^{* * *}$ & $0.007^{* * *}$ & $0.002^{* * *}$ \\
\hline & $(0.003)$ & $(0.002)$ & $(0.001)$ & $(0.001)$ \\
\hline \multirow{2}{*}{ High edu. men ${ }^{\star} 2005$} & $0.112^{\star \star *}$ & $0.062^{* * *}$ & $0.018^{\star * *}$ & $0.004^{* * *}$ \\
\hline & $(0.004)$ & $(0.003)$ & $(0.002)$ & $(0.001)$ \\
\hline \multirow{2}{*}{ Age } & $-0.102^{\star * *}$ & $-0.013^{* * *}$ & $-0.002^{* * *}$ & $-0.001^{\star * *}$ \\
\hline & $(0.000)$ & $(0.000)$ & $(0.000)$ & $(0.000)$ \\
\hline \multirow{2}{*}{ Constant } & $2.845^{* * *}$ & $0.445^{* * *}$ & $0.100^{* * *}$ & $0.052^{* * *}$ \\
\hline & $(0.006)$ & $(0.007)$ & $(0.005)$ & $(0.005)$ \\
\hline Observations & 819,055 & 589,339 & 585,633 & 472,810 \\
\hline Adjusted- $\mathrm{R}^{2}$ & 0.271 & 0.041 & 0.013 & 0.008 \\
\hline
\end{tabular}

Note: 1) Data source: Census 1990-2005; 2) All regressions include province fixed effects; 3) Robust standard errors in parentheses, ${ }^{* *} \mathrm{p}<0.01,{ }^{* *} \mathrm{p}<0.05,{ }^{*} \mathrm{p}<0.1$. 
Table 4. OLS: Trend of marriage market (rural).

\begin{tabular}{|c|c|c|c|c|}
\hline Dependent variable: Being single $=1$ & (1) & (2) & (3) & (4) \\
\hline Age group & $23-29$ & $30-34$ & $35-39$ & $40-44$ \\
\hline \multirow{2}{*}{ Low edu. women ${ }^{\star} 2000$} & $0.061^{\star * *}$ & $0.004^{* * *}$ & $0.001^{\star * *}$ & $0.001^{* * *}$ \\
\hline & $(0.001)$ & $(0.000)$ & $(0.000)$ & $(0.000)$ \\
\hline \multirow{2}{*}{ Low edu. women ${ }^{\star} 2005$} & $0.067^{\star * *}$ & $0.009^{* * *}$ & $0.003^{* * *}$ & $0.002^{\star * *}$ \\
\hline & $(0.001)$ & $(0.000)$ & $(0.000)$ & $(0.000)$ \\
\hline \multirow{2}{*}{ Low edu. men } & $0.155^{\star * *}$ & $0.092^{* * *}$ & $0.074^{* * *}$ & $0.067^{* * *}$ \\
\hline & $(0.001)$ & $(0.001)$ & $(0.000)$ & $(0.001)$ \\
\hline \multirow{2}{*}{ Low edu. men ${ }^{\star} 2000$} & $0.090^{* * *}$ & $-0.018^{* * *}$ & $-0.023^{\star * *}$ & $-0.011^{\star * *}$ \\
\hline & $(0.001)$ & $(0.001)$ & $(0.001)$ & $(0.001)$ \\
\hline \multirow{2}{*}{ Low edu. men ${ }^{\star} 2005$} & $0.122^{* * *}$ & $0.008^{\star * *}$ & $-0.018^{* * *}$ & $-0.024^{* * *}$ \\
\hline & $(0.002)$ & $(0.001)$ & $(0.001)$ & $(0.001)$ \\
\hline \multirow{2}{*}{ High edu. women } & $0.106^{* * *}$ & 0.001 & 0.001 & $0.003^{*}$ \\
\hline & $(0.002)$ & $(0.001)$ & $(0.001)$ & $(0.001)$ \\
\hline \multirow{2}{*}{ High edu. women ${ }^{\star} 2000$} & $0.103^{* * *}$ & $0.019^{* * *}$ & $0.002^{* * *}$ & $-0.003^{* *}$ \\
\hline & $(0.003)$ & $(0.001)$ & $(0.001)$ & $(0.001)$ \\
\hline \multirow{2}{*}{ High edu. women ${ }^{\star} 2005$} & $0.140^{\star * *}$ & $0.036^{* * *}$ & $0.010^{* * *}$ & -0.001 \\
\hline & $(0.005)$ & $(0.003)$ & $(0.002)$ & $(0.002)$ \\
\hline \multirow{2}{*}{ High edu. men } & $0.127^{\star * *}$ & $0.021^{* * *}$ & $0.018^{* * *}$ & $0.016^{* * *}$ \\
\hline & $(0.001)$ & $(0.001)$ & $(0.001)$ & $(0.001)$ \\
\hline \multirow{2}{*}{ High edu. men ${ }^{\star} 2000$} & $0.193^{* * *}$ & $0.023^{* * *}$ & $-0.005^{\star * *}$ & $-0.007^{\star * \star}$ \\
\hline & $(0.002)$ & $(0.001)$ & $(0.001)$ & $(0.001)$ \\
\hline \multirow{2}{*}{ High edu. men ${ }^{\star 2} 2005$} & $0.240^{* * *}$ & $0.056^{* * *}$ & $0.005^{* *}$ & $-0.005^{* * *}$ \\
\hline & $(0.004)$ & $(0.003)$ & $(0.002)$ & $(0.002)$ \\
\hline \multirow{2}{*}{ Age } & $-0.061^{\star * *}$ & $-0.006^{* * *}$ & $-0.002^{\star * *}$ & $-0.000^{* * *}$ \\
\hline & $(0.000)$ & $(0.000)$ & $(0.000)$ & $(0.000)$ \\
\hline \multirow{2}{*}{ Constant } & $1.667^{\star * *}$ & $0.189^{* * *}$ & $0.058^{* * *}$ & $0.021^{\star * \star}$ \\
\hline & $(0.003)$ & $(0.004)$ & $(0.004)$ & $(0.005)$ \\
\hline Observations & $2,432,557$ & $1,642,536$ & $1,624,238$ & $1,199,157$ \\
\hline Adjusted- $\mathrm{R}^{2}$ & 0.170 & 0.044 & 0.035 & 0.034 \\
\hline
\end{tabular}

Note: 1) Data source: Census 1990-2005; 2) All regressions include province fixed effects; 3) Robust standard errors in parentheses, ${ }^{* * *} \mathrm{p}<0.01,{ }^{* *} \mathrm{p}<0.05,{ }^{*} \mathrm{p}<0.1$.

education group before age 30, and the gap broadened through years. For women, the gap across education group was $16.2 \%$ in 1990 but $17.8 \%$ in 2005 , for men it was $9.7 \%$ in 1990 but $12.2 \%$ in 2005 . The expansion corresponds with increasing return to education in labor market ( $\mathrm{Li}, 2012$, [12]), as individuals might tend to spend more time in labour market than searching for marriage match. The gender difference in single rate of high educated group increased from $13.8 \%$ in 1990 to $15.3 \%$ in 2005 , implying that high educated men are more likely to be single before age 30 compared to high educated women, which shows 
a negative evidence of leftover women.

Comparing the results in column 2 and 3, we noted that the coefficients significantly decreased as age increases. For highly educated women, the coefficient dropped from $16.2 \%$ for age 23 - 29 to $4.7 \%$ for those aged $30-34,1.9 \%$ for the age group 35 - 39. It further shrinks as the year passes, showing that the difference in single rate across education groups was narrowing for senior population in recent years. Considering gender difference in the high education group, the single rate was $1.8 \%$ higher for women aged 35 to 39 in 1990 but $5.3 \%$ higher for men in 2005. There was no evidence supporting the leftover women in latest marriage market.

Table 4 shows the regression results using rural population. We observed significantly higher single rate for low educated men in all age groups. The gender gap in 1990 was $9.2 \%$ for age 30 - 34 and $6.7 \%$ for age 40 - 44, supporting leftover men. However, we found that the gender gap in rural low education group was decreasing as the year passes. This is probably due to the increasing labor migration, allowing more opportunities for rural individuals to get in touch with peers. Meanwhile, the urban low education group showed an increasing gender gap in single rate. That is, from $3.9 \%$ in 1990 to $7.9 \%$ in 2005 for age $30-34$, from $1.1 \%$ to $2.8 \%$ for age $35-39$ and from $0.7 \%$ to $1.8 \%$ for age $40-44$. The findings indicate that leftover men might not be just for rural market, as the single rate of urban low educated men was also increasing comparatively.

From the former results, we found that high educated women postponed marriage but showed no significant difference in single rate than other subgroups after age 35, while low educated men showed significantly higher single rate than counterparts for all age groups considered. To study the possible reason of leftover women and leftover men, we further explored the trend of comparative supply in marriage market introduced by Becker (1973) [13].

The demographic structure and education composition of Chinese population have shifted dramatically since 1990s. On one hand, the widely discussed soaring sex ratio at birth of China leads to increasing comparative supply of men in the marriage market (Figure 4), especially for rural areas (Yuan X, et al., 2005, [14]). On the other hand, the average education level of Chinese population has increased substantially since the education reform started in 1980s. The reform affects men and women differently. From Figure 5 we can see that the percentage of female in college graduates increased from less than $30 \%$ in late 1980 s to more than $50 \%$ in 2010s, showing that the comparative supply of high educated women increased throughout the years.

Before considering the impact of shifting comparative supply in marriage market on individual marriage decisions, we need to explore the matching pattern of Chinese couples. Using matched couple data from 1990, 2000 and 2005 census, we show the matching pattern considering education level for all couples of which wife's age ranged between 20 and 40 in Table 5. We observed that Chinese women tend to marry-up, and men tend to marry-down considering education. The percentage of urban women married to high educated men increased 


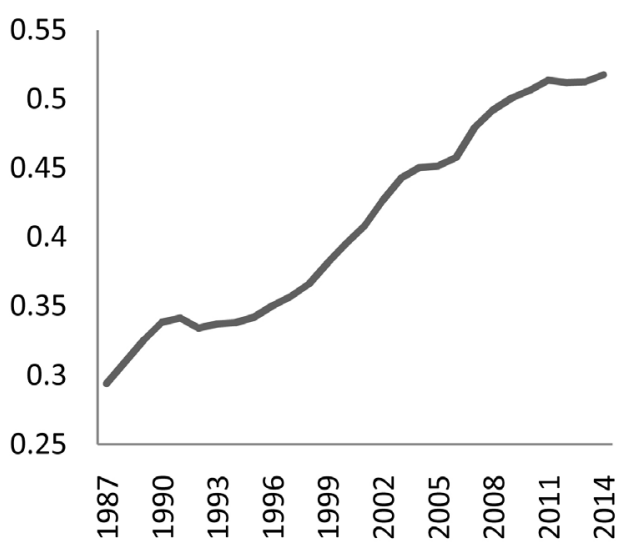

Figure 4. Sex ratio at birth (1985-2011, female = 100). Data source: National bureau of statistics.

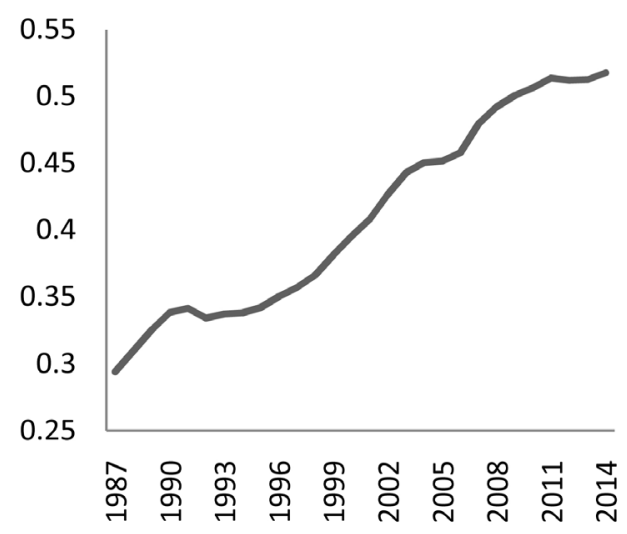

Figure 5. Percentage of female in college graduates. Data source: National bureau of statistics.

Table 5. Education matching pattern of married couples.

\begin{tabular}{cccc}
\hline \multirow{2}{*}{ Census year } & \multirow{2}{*}{ Wife's education level } & \multicolumn{2}{c}{ Husband's education level } \\
\cline { 3 - 4 } & & Low & High \\
\hline \multirow{2}{*}{1990} & Low & & \\
& High & $86.10 \%$ & $9.20 \%$ \\
\multirow{2}{*}{2000} & Low & $1.80 \%$ & $3.00 \%$ \\
& High & $69.70 \%$ & $13.00 \%$ \\
\multirow{2}{*}{2005} & Low & $4.20 \%$ & $13.10 \%$ \\
& High & $61.10 \%$ & $12.20 \%$ \\
& & $5.60 \%$ & $21.00 \%$ \\
\hline \multirow{2}{*}{1990} & Low & & $9.18 \%$ \\
& High & $86.42 \%$ & $1.87 \%$ \\
\multirow{2}{*}{2000} & Low & $2.52 \%$ & $9.84 \%$ \\
& High & $85.51 \%$ & $2.00 \%$ \\
& Low & $2.66 \%$ & $6.81 \%$ \\
& High & $90.04 \%$ & $1.37 \%$ \\
\hline
\end{tabular}

Data source: Census 1990-2005. 
while the percentage of rural low educated men married to high educated women dropped through the years. We also explored the matching pattern considering hukou type and found that the percentage of cross-hukou-type marriage is extremely low and decreasing through years, possibly because the hukou type could be changed through marriage. So we considered urban and rural as two separate marriage markets in following discussions. The matching pattern considering age is more straightforward, husbands are at average about 2 years older than their wives?

The ladder-type matching pattern considering education could lead to structural matching failure of high educated women and low educated men. The situation could be worse as the comparative supply of these two groups increased through the years as we discussed earlier. We will try to explore whether the change in comparative supply could explain the trend we observed in following discussions.

To measure the comparative supply each individual faces in actual marriage market, we employed the sex ratio of the group with same province, hukou, and the corresponding education and age group. For example, consider a 25 year old urban high educated women, the comparative supply of her group would be the number of urban women both high educated and low educated aged 22 to 25 divided by the number of urban high educated men aged 25 to 28 , referred to as female share. Similarly, for the group of 25 years old rural low educated men, the comparative supply would be the number of rural men both high educated and low educated age 25 to 28 divided by the number of rural low educated women age 22 to 25 , referred to as male share. The LPM model was adapted to explore the effect of comparative supply on marriage decision:

$$
\begin{aligned}
& \operatorname{Pr}\left(\text { single }=1 \mid X_{i}\right)_{p}=\beta_{0}+\beta_{1} \text { gender }_{i} * \text { education }_{i}+\beta_{2} \text { gender }_{i} * \text { sexratio }_{i, p} \\
& +\beta_{3} \text { gender }_{i}+\beta_{4} \text { education }_{i}+\beta_{4} \text { sexratio }_{i, p, t}+\gamma_{1} Y_{i}+\gamma_{2} Z_{p}+\varepsilon_{i, p}
\end{aligned}
$$

From the model, the dependent variable is marriage status for individual $i$, assigned as 1 for being single and 0 as with marriage experience; gender ${ }_{i}$ describes individual's gender, female assigned as 1 while considering the impact of comparative supply on female's marriage choice, male assigned as 1 while considering the impact of comparative supply on male's marriage choice; education ${ }_{\mathrm{i}}$ describes individual's education level, high educated assigned as 1 while considering the impact of comparative supply on the marriage choice of high educated, low educated assigned as 1 while considering the impact of comparative supply

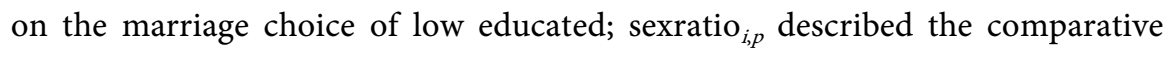
supply individual i's group facing, equals female share while considering female's marriage choice, male share for male; $Y_{i}$ describes individual i's personal characteristics, including age; $Z_{p}$ is the province fixed effect and $\varepsilon_{i, p}$ is the random component.

Table 6 shows the result exploring the impact of female share on marriage

${ }^{7}$ Tables showing the matching pattern considering age and hukou type are available on request. 
Table 6. Marriage decision and female share (urban).

\begin{tabular}{|c|c|c|c|c|c|c|}
\hline \multirow{2}{*}{ D.V.: Being single $=1$} & \multicolumn{2}{|c|}{1990} & \multicolumn{2}{|c|}{2000} & \multicolumn{2}{|c|}{2005} \\
\hline & (1) & (2) & (3) & (4) & (5) & (6) \\
\hline \multicolumn{7}{|c|}{ Age: 23 - 29} \\
\hline \multirow{2}{*}{ Female * high edu. } & $0.060^{* * *}$ & 0.002 & $0.031^{\star \star \star}$ & $-0.041^{\star * *}$ & $0.054^{\star * *}$ & $0.104^{* * *}$ \\
\hline & $(0.004)$ & $(0.008)$ & $(0.003)$ & $(0.008)$ & $(0.006)$ & $(0.013)$ \\
\hline \multirow{2}{*}{ High edu. } & $0.100^{\star * *}$ & $0.107^{\star * *}$ & $0.097^{\star * *}$ & $0.084^{* * *}$ & $0.126^{* * *}$ & $0.135^{\star * \star}$ \\
\hline & $(0.003)$ & $(0.003)$ & $(0.002)$ & $(0.004)$ & $(0.005)$ & $(0.009)$ \\
\hline Female * female & & $0.119^{* * *}$ & & -0.017 & & -0.020 \\
\hline share & & $(0.005)$ & & $(0.014)$ & & $(0.019)$ \\
\hline \multirow{2}{*}{ Female share } & & $-0.108^{\star \star \star}$ & & $0.052^{* * *}$ & & -0.015 \\
\hline & & $(0.005)$ & & $(0.014)$ & & $(0.019)$ \\
\hline Adjusted- $R^{2}$ & 0.254 & 0.255 & 0.268 & 0.268 & 0.279 & 0.279 \\
\hline \multicolumn{7}{|c|}{ Age: 30 - 34} \\
\hline \multirow{2}{*}{ Female $*$ high edu. } & $0.057^{* * *}$ & $0.040^{* * *}$ & $0.021^{* * *}$ & $0.010^{* *}$ & $0.024^{* * *}$ & -0.012 \\
\hline & $(0.004)$ & $(0.012)$ & $(0.002)$ & $(0.005)$ & $(0.005)$ & $(0.011)$ \\
\hline \multirow{2}{*}{ High edu. } & $-0.008^{* * *}$ & $-0.005^{\star * *}$ & $-0.011^{\star * *}$ & -0.003 & $-0.011^{* * *}$ & 0.010 \\
\hline & $(0.002)$ & $(0.002)$ & $(0.001)$ & $(0.002)$ & $(0.004)$ & $(0.007)$ \\
\hline \multirow{2}{*}{$\begin{array}{c}\text { Female } * \text { female } \\
\text { share }\end{array}$} & & $0.066^{\star * *}$ & & $0.044^{* * *}$ & & $0.087^{\star * *}$ \\
\hline & & $(0.006)$ & & $(0.008)$ & & $(0.024)$ \\
\hline \multirow{2}{*}{ Female share } & & $-0.064^{* * *}$ & & $-0.043^{* * *}$ & & $-0.079^{\star * *}$ \\
\hline & & $(0.006)$ & & $(0.008)$ & & $(0.024)$ \\
\hline Adjusted- $\mathbf{R}^{2}$ & 0.042 & 0.043 & 0.034 & 0.034 & 0.046 & 0.046 \\
\hline \multicolumn{7}{|c|}{ Age: 35 - 39} \\
\hline \multirow{2}{*}{ Female $*$ high edu. } & $0.029^{* * *}$ & $0.045^{\star * *}$ & $0.020^{\star * *}$ & $0.014^{* * *}$ & $0.025^{\star * *}$ & $0.023^{* * *}$ \\
\hline & $(0.003)$ & $(0.011)$ & $(0.001)$ & $(0.002)$ & $(0.003)$ & $(0.007)$ \\
\hline \multirow{2}{*}{ High edu. } & $-0.010^{\star * *}$ & $-0.009^{\star * *}$ & $-0.014^{\star * *}$ & $-0.010^{\star * *}$ & $-0.017^{\star * *}$ & $-0.007^{\star \star}$ \\
\hline & $(0.001)$ & $(0.001)$ & $(0.001)$ & $(0.001)$ & $(0.002)$ & $(0.003)$ \\
\hline \multirow{2}{*}{$\begin{array}{c}\text { Female } * \text { female } \\
\text { share }\end{array}$} & & $0.026^{\star * *}$ & & $0.024^{\star * *}$ & & $0.040^{\star * *}$ \\
\hline & & $(0.004)$ & & $(0.002)$ & & $(0.011)$ \\
\hline \multirow{2}{*}{ Female share } & & $-0.028^{\star * *}$ & & $-0.023^{* * *}$ & & $-0.044^{* * *}$ \\
\hline & & $(0.004)$ & & $(0.002)$ & & $(0.011)$ \\
\hline Adjusted- $\mathrm{R}^{2}$ & 0.009 & 0.010 & 0.012 & 0.012 & 0.015 & 0.016 \\
\hline
\end{tabular}

Note: 1) Data source: Census 1990-2005; 2) All regressions include gender, age and province fixed effects; 3 ) Robust standard errors in parentheses, ${ }^{* *} \mathrm{p}<0.01,{ }^{* *} \mathrm{p}<0.05,{ }^{*} \mathrm{p}<0.1$.

choice of urban high educated women by census year and age group, while Table 7 shows the results considering the effect of male share on rural low educated men ${ }^{8}$.

Columns 1, 3 and 5 in Table 6 are the basic regression on gender interacted ${ }^{8}$ Regression results considering urban low educated male and rural high educated female are available on request. 
Table 7. Marriage decision and male share (rural).

\begin{tabular}{|c|c|c|c|c|c|c|}
\hline \multirow{2}{*}{ D.V.: Being single $=1$} & \multicolumn{2}{|c|}{1990} & \multicolumn{2}{|c|}{2000} & \multicolumn{2}{|c|}{2005} \\
\hline & (1) & (2) & (3) & (4) & (5) & (6) \\
\hline \multicolumn{7}{|c|}{ Age: $23-29$} \\
\hline \multirow{2}{*}{ Male $*$ low edu. } & $0.226^{* * *}$ & $-0.054^{* *}$ & $0.099^{* * *}$ & $-0.183^{* * *}$ & $0.095^{* * *}$ & $0.240^{\star * *}$ \\
\hline & $(0.027)$ & $(0.026)$ & $(0.014)$ & $(0.015)$ & $(0.016)$ & $(0.018)$ \\
\hline \multirow{2}{*}{ Low edu. } & $-0.397^{* * *}$ & $-0.107^{* * *}$ & $-0.330^{* * *}$ & $-0.042^{* * *}$ & $-0.319^{* * *}$ & $-0.481^{* * *}$ \\
\hline & $(0.022)$ & $(0.022)$ & $(0.012)$ & $(0.013)$ & $(0.013)$ & $(0.015)$ \\
\hline \multirow{2}{*}{ Male $*$ male share } & & $0.233^{* * *}$ & & $0.175^{\star * *}$ & & $-0.086^{\star * *}$ \\
\hline & & $(0.003)$ & & $(0.005)$ & & $(0.013)$ \\
\hline \multirow{2}{*}{ Male share } & & $-0.394^{* * *}$ & & $-0.270^{* * *}$ & & $0.214^{\star * *}$ \\
\hline & & $(0.004)$ & & $(0.004)$ & & $(0.010)$ \\
\hline Adjusted- $R^{2}$ & 0.131 & 0.137 & 0.190 & 0.193 & 0.205 & 0.207 \\
\hline \multicolumn{7}{|c|}{ Age: $30-34$} \\
\hline \multirow{2}{*}{ Male $*$ low edu. } & $0.081^{* * *}$ & $0.066^{* * *}$ & $0.038^{* * *}$ & $-0.034^{\star *}$ & $0.080^{* * *}$ & $0.066^{\star *}$ \\
\hline & $(0.020)$ & $(0.020)$ & $(0.014)$ & $(0.014)$ & $(0.025)$ & $(0.027)$ \\
\hline \multirow{2}{*}{ Low edu. } & -0.024 & -0.011 & $-0.041^{* * *}$ & $0.029^{* *}$ & $-0.103^{\star * \star}$ & $-0.093^{\star * *}$ \\
\hline & $(0.018)$ & $(0.018)$ & $(0.012)$ & $(0.012)$ & $(0.022)$ & $(0.023)$ \\
\hline \multirow{2}{*}{ Male $*$ male share } & & $0.028^{\star * *}$ & & $0.118^{* * *}$ & & $0.066^{* * *}$ \\
\hline & & $(0.002)$ & & $(0.005)$ & & $(0.010)$ \\
\hline \multirow{2}{*}{ Male share } & & $-0.013^{* * *}$ & & $-0.077^{* * *}$ & & -0.011 \\
\hline & & $(0.001)$ & & $(0.004)$ & & $(0.008)$ \\
\hline Adjusted- $\mathrm{R}^{2}$ & 0.042 & 0.042 & 0.037 & 0.038 & 0.050 & 0.050 \\
\hline \multicolumn{7}{|c|}{ Age: 35 - 39} \\
\hline \multirow{2}{*}{ Male * low edu. } & $0.095^{*}$ & 0.073 & $0.038^{\star * *}$ & $0.038^{* * *}$ & $0.055^{* * *}$ & 0.026 \\
\hline & $(0.052)$ & $(0.052)$ & $(0.010)$ & $(0.011)$ & $(0.016)$ & $(0.017)$ \\
\hline \multirow{2}{*}{ Low edu. } & -0.055 & -0.035 & $-0.023^{* * *}$ & $-0.024^{\star * *}$ & -0.018 & 0.011 \\
\hline & $(0.051)$ & $(0.051)$ & $(0.009)$ & $(0.009)$ & $(0.015)$ & $(0.016)$ \\
\hline \multirow{2}{*}{ Male $*$ male share } & & $0.062^{* * *}$ & & $0.022^{* * *}$ & & $0.038^{* * *}$ \\
\hline & & $(0.004)$ & & $(0.002)$ & & $(0.008)$ \\
\hline \multirow{2}{*}{ Male share } & & $-0.025^{* * *}$ & & -0.001 & & $-0.034^{\star * *}$ \\
\hline & & $(0.004)$ & & $(0.003)$ & & $(0.007)$ \\
\hline Adjusted- $\mathrm{R}^{2}$ & 0.037 & 0.038 & 0.024 & 0.024 & 0.030 & 0.030 \\
\hline
\end{tabular}

Note: 1) Data source: Census 1990-2005; 2) All regressions include gender, age and province fixed effects; 3 ) Robust standard errors in parentheses, ${ }^{* * *} \mathrm{p}<0.01,{ }^{* *} \mathrm{p}<0.05,{ }^{*} \mathrm{p}<0.1$.

with education level, from which we observed that high educated women showed significantly higher possibility of being single. Columns 2, 4 and 6 added female share and the interaction with gender, which show that for women facing increasing comparative supply, the probability of being single significantly increased. For the group aged 23 to 29 in 1990 and age 30 to 34 in 2005, the change in the comparative supply explained the effect of higher education on marriage 
choice; for age 30 to 34 in 2000, the coefficients on the interaction in terms of gender and high education dropped more than 52\% after adding the female share variables. As shown above, this cohort had experienced the education reform which started in 1980s, so the shifting comparative supply might be more effective. For the population aged 35 to 39 , adding the female share showed no clear impact on the coefficients of high education, and the $\mathrm{R}^{2}$ of the model is obviously smaller than younger groups, indicating that for senior population, competence in the market has limited explaining power on individual choices.

Similarly for Table 7, the basic regressions show that the low educated men were more likely to be single (see columns $1,3,5$ ). Adding the control of male share and the interaction with male, for age 23 to 29 in 1990 and 2000, the coefficient of male interacted with low education became significantly negative, showing that the excess supply of low educated men in the market entirely explained the positive effect of low education on single rate of rural men. The change in comparatively supply explained $17.5 \%-18.5 \%$ of the impact of low education on men age 30 to 34 in 1990 and 2005, and also the whole positive effect for men age 35 to 39 in 1990 and 2005.

Briefly, the shifting comparative supply in the marriage market could partially explain the comparatively higher possibility of being single for urban high educated women aged 23 to 35 and rural low educated men of all age groups. The changes of demographic structure and education level of Chinese population during the years was the main cause of the phenomena observed in marriage market, as high educated women postponing marriage and low educated men being leftover. Besides whether to get married or not and when to get married, who to get married with is also an important consideration. Using the matched couple data, we attempted to explore whether there was difference in the age gap between the couple and the spouse's education level between people who get married earlier in life and later for urban population', which may give us some hint on the marriage choice of high educated women.

Figure 6 displays the percentage of individuals whose spouses were more than 3 years older/younger (for women/men) at the time of marriage. It is clear that men who got married early tend to marry with women of the similar age range. But as their age increases, more men tend to marry with younger women, with the percentage stayed comparatively steady after age 30 . For women the trend was totally different; young wives were more likely to be married with older husbands. Women who got married between 25 to 30 tend to marry with men of the similar age range, with the percentage being lower for high educated; while for women who got married after age 30, the percentage of getting married with an older husband increased with marriage age. Figure 7 shows the percentage of individuals whose spouse are high educated by the age of marriage. For men, the possibility of marrying high educated women is increasing with age, however for women, it is dropping for all education group after age 26.

${ }^{9}$ Figures for rural population are available on request. 


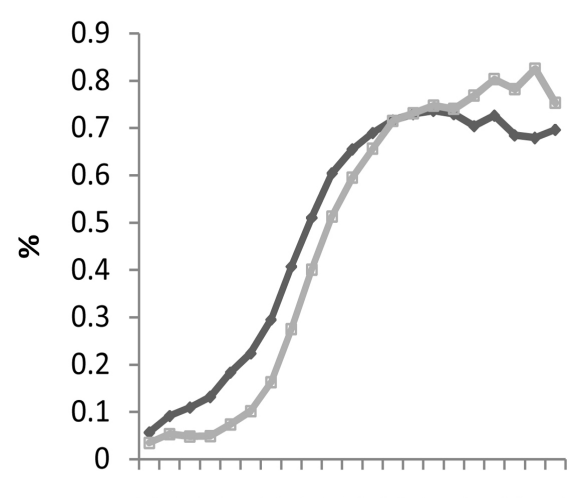

2022242628303234363840

marriage age

$\longrightarrow$ low edu $\quad$ high edu

(a)

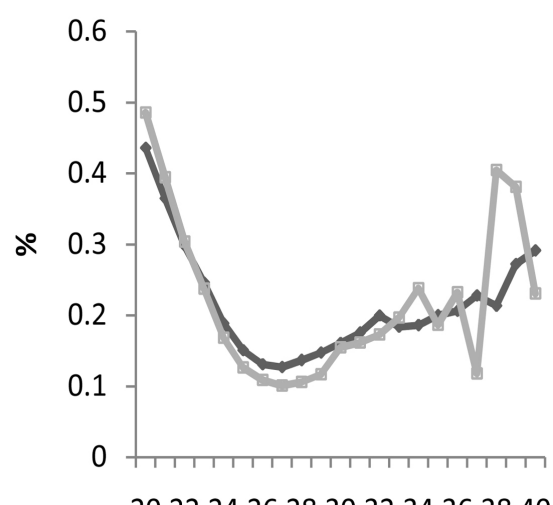

2022242628303234363840

marriage age

$\multimap$ low edu $\_$high edu

(b)

Figure 6. \% of couples which husband's age is 3 or more years older than wife. (a) x-axis: husband's marriage age. (b) x-axis: wife's marriage age. Data source: Census 2000-2005.

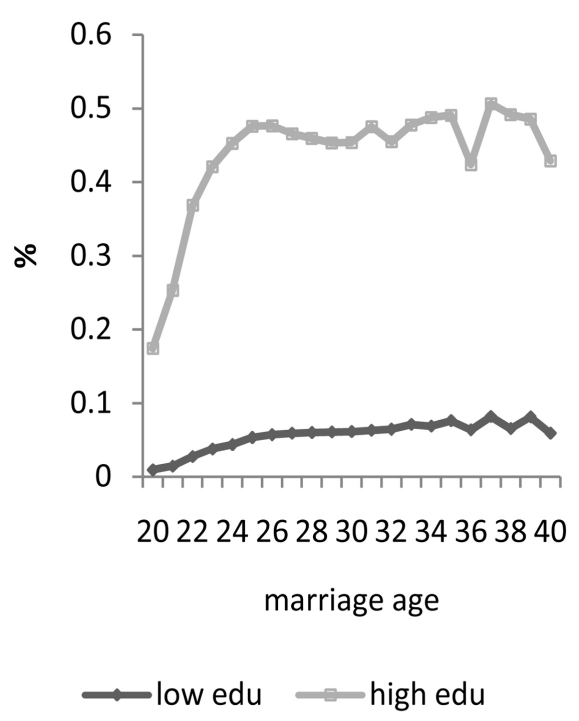

(a)

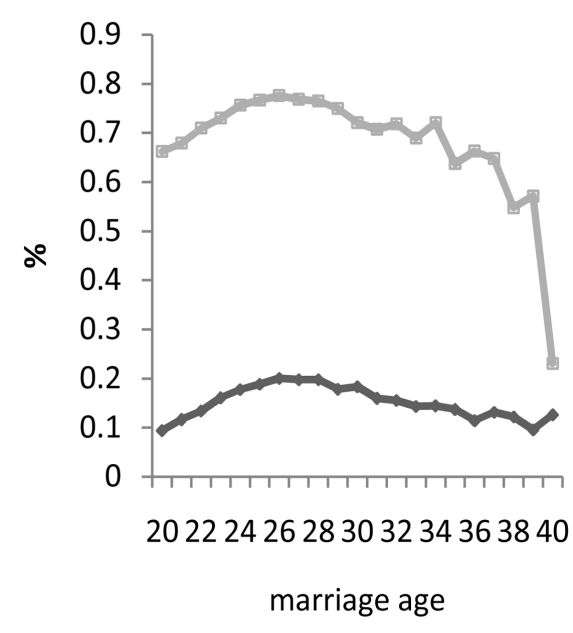

$\longrightarrow$ low edu $\cong$ high edu

(b)

Figure 7. \% married to high educated individual. (a) x-axis: husband's marriage age. (b) x-axis: wife's marriage age. Data source: Census 2000-2005.

To summarize, women who get married later in life have higher possibility to match with older spouse and lower possibility to match with high educated men, and the effect tend to be more severe for high educated women, while men showed no such trend. That is to say, although high educated women might not show significant difference in lifetime single rate than other sub-group population, they may have to sacrifice the quality of marriage for postponing their marriage. High educated women who were unable to make a fulfilling match in earlier years in the market, could lower their standard in order to avoid becoming leftover women. 


\section{Conclusions and Discussion}

Using the NBS census datasets from 1990 to 2010, we showed the trend of single rates in the Chinese marriage market. Overall, the single rate of population aged 23 to 29 increased throughout the years, as well as the differences across education levels. Empirically, we found that urban high educated women tended to postpone their marriage but showed no significant difference than other subgroups in single rate after age 35, providing no evidence for leftover women. Meanwhile, low educated men, in both urban and rural areas, showed consistently higher single rates than other population groups, supporting the view of leftover men. Further exploring the issue of marriage decision, we conclude that shifting comparative supply caused by demographic change and education reform could partially or wholly explain the phenomenon observed above.

High single rate for low educated men is not only a loss in welfare of the group, but it could also have negative effect on the stability of society. High marriage rate for low educated women along with the loosening of birth control policies could lead to a cluster in low income population and increasing inequality. The decrease in marriage quality of high educated women who get married later in life is also of interest for people concerning the welfare level of the whole society. Policies designed to encourage marriage should take all perspectives into consideration, while one key element should be eliminating discrimination and protecting free choice of marriage. As the Chinese population is becoming more educated and more skewed in sex ratio and age structure, facing continuously shifts in comparative supply in marriage market, there is the need to obtain more recent data to support future discussion on single rates and marriage choices.

\section{References}

[1] Li, S. (2007) Imbalanced Sex Ratio at Birth and Comprehensive Intervention in China. Proceedings of 4 th Asia Pacific Conference on Reproductive and Sexual Health and Rights, Hyderabad, 29-31 October 2007, 1-16.

[2] Loh, C. and Remick, E.J. (2015) China's Skewed Sex Ratio and the One-Child Policy. The China Quarterly, 222, 295-319. https://doi.org/10.1017/S0305741015000375

[3] Tuljapurkar, S., Li, N. and Feldman, M.W. (1995) High Sex Ratios in China's Future. Science, 267, 874. https://doi.org/10.1126/science.7846529

[4] Wei, S.J. and Zhang, X. (2011) The Competitive Saving Motive: Evidence from Rising Sex Ratios and Savings Rates in China. Journal of political Economy, 119, 511 564. https://doi.org/10.1086/660887

[5] Edlund, L., Li, H., Yi, J., et al. (2013) Sex Ratios and Crime: Evidence from China. Review of Economics and Statistics, 95, 1520-1534.

https://doi.org/10.1162/REST_a_00356

[6] Goldstein, J.R. and Kenney, C.T. (2001) Marriage Delayed or Marriage Forgone? New Cohort Forecasts of First Marriage for U.S. Women. American Sociological Review, 66, 506-519. https://doi.org/10.2307/3088920

[7] Lundberg, S. and Pollak, R.A. (2007) The American Family and Family Economics. The Journal of Economic Perspectives, 21, 3-26. https://doi.org/10.1257/jep.21.2.3 
[8] Qian, Y. and Qian, Z. (2014) The Gender Divide in Urban China: Singlehood and Assortative Mating by Age and Education. Demographic Research, 31, 1337-1364. https://doi.org/10.4054/DemRes.2014.31.45

[9] Bauer, J., Feng, W., Riley, N.E., et al. (1992) Gender Inequality in Urban China: Education and Employment. Modern China, 18, 333-370. https://doi.org/10.1177/009770049201800304

[10] Wu, Y. and Liu, Q. (2014) The Impact of Higher Education Expansion on the Marriage Market: Single Women? Single Men? China Economic Quarterly, 14, 5-30.

[11] Zhang, Y., Zhang, B. and Hu, F. (2015) Leftover Women or Leftover Men: The Difference of Marriage Match and the Price of Leftover. Population \& Economics, 5, 13-24.

[12] Li, H. (2012) China's Return to Education. Policy Research \& Exploration, 20, 65-66.

[13] Becker, G.S. (1973) A Theory of Marriage. National Bureau of Economic Research, Cambridge.

[14] Yuan, X. and Shi, H. (2005) Abnormal High Sex Ratios at Birth and the Family Planning Policy in China. Population Research, 29, 11-17.

\section{Submit or recommend next manuscript to SCIRP and we will provide best service for you:}

Accepting pre-submission inquiries through Email, Facebook, LinkedIn, Twitter, etc. A wide selection of journals (inclusive of 9 subjects, more than 200 journals)

Providing 24-hour high-quality service

User-friendly online submission system

Fair and swift peer-review system

Efficient typesetting and proofreading procedure

Display of the result of downloads and visits, as well as the number of cited articles

Maximum dissemination of your research work

Submit your manuscript at: http://papersubmission.scirp.org/

Or contact jss@scirp.org 